\title{
Characterization and radionuclide sorption of suspended particulate matters in freshwater according to their settling kinetics
}

\author{
C. Brach-Papa ${ }^{1}$, P. Boyer ${ }^{1}$, M. Amielh ${ }^{2}$ and F. Anselmet ${ }^{2}$ \\ ${ }^{1}$ Institut de Radioprotection et de Sûreté Nucléaire, Laboratoire de Modélisation \\ Environnementale (DEI/SECRE), CE Cadarache, 13115 Saint Paul-Lez-Durance, France \\ ${ }^{2}$ Institut de Recherche sur les Phénomènes Hors Équilibre, Technopôle de Château \\ Gombert, 49 rue F. Joliot-Curie, BP. 146, Marseille Cedex 13, France
}

\begin{abstract}
In freshwater, radionuclide transfers depend both on exchanges between liquid and solid phases and on mass transfers between suspended and bottom sediment. Whereas the former ones depend on chemical processes (sorption/desorption, complexation...), the latter ones are regulated by hydrological and sedimentary considerations (dispersion, erosion, deposit...) closely related to the interactions between flow, suspended matter and bed sediment. Previous studies highlight the need to consider the matter heterogeneity and its specific sediment dynamics to correctly report the in homogeneity of fluxes in time and in space. These considerations lead us to develop an experimental method to distinguish the different particle groups present in natural water, mainly according to their settling kinetics. In this context, this paper presents the experimental protocol TALISMEN to characterize a natural bulk suspension according to its main settling kinetics groups. In a first step, this identification is achieved by the use of a settling tank that allows the monitoring of the suspended solid concentrations at various depths, combined to a settling model applying a multi-class approach. In a second step, the particle groups are isolated and characterized. The sorption property of each group toward ${ }^{137} \mathrm{Cs}$ is determined by estimation of its distribution coefficients $\left(\mathrm{k}_{\mathrm{d}}\right)$ and sorption kinetics.
\end{abstract}

\section{INTRODUCTION}

In freshwater systems, the accumulation and the dissemination of radionuclides and heavy metals associated to suspended particulate matters SPM and bottom sediment depend on several processes. These processes act during the formation of bottom sediment (deposition, erosion, consolidation), during exchanges of pollutants between liquid and solid phases (sorption, desorption) as well as during dispersion all along the stream. Usually, the solid phase is decomposed into cohesive and non-cohesive materials. In freshwater systems, cohesive sediment, in particular, clays and silts, is mainly made of mineral phases containing aluminosilicates with large specific surfaces [1]. These fine materials have a high sorption rate towards organic and inorganic xenobiotics [2]. On the opposite, non-cohesive particles are made of detritical materials containing quartz having low specific surfaces [3]. The percentage of organic carbon can also vary quite largely according to the considered granulometric class. These properties highlight the heterogeneity of a natural suspension from the point of view of its chemical and dynamical behaviours.

In this context, new numerical tools for modelling pollutant transfers within continental hydrosystems, such as CASTEAUR, use multi-class approaches [4]. These approaches make it possible to take into account sediment heterogeneity with regard to their hydrodynamics-sedimentary and chemical characteristics [5]. These considerations are particularly important for the evaluation of the deposit fluxes that are the main processes for the constitution of stocks of pollutants such as radionuclides, in the deposition areas along the rivers [6]. The hydrodynamic-sedimentary behaviour 
of suspended particulate matter can be described by the criterion of an effective settling velocity We [7]. In calm water condition, this criterion characterizes the clearance rate of the suspended solid concentration SSC over the water column. The sorption properties of SPM towards radionuclides are commonly characterised by the use of the distribution coefficient $K d$, defined as the ratio between sorbed and aqueous radionuclide concentrations.

$$
K d=\frac{[M]_{s}}{[M]_{w}}
$$

$\begin{array}{llll}\text { With: } & K d & \text { distribution coefficient } & \left(\mathrm{L}^{\mathrm{kg}} \mathrm{gg}^{-1}\right) \\ & {[\mathrm{M}]_{s}} & \text { sorbed radionuclide concentration } & \left(\mathrm{Bq} \cdot \mathrm{kg}^{-1}\right) \\ & {[\mathrm{M}]_{w}} & \text { aqueous radionuclide concentration } & \left(\mathrm{Bq} . \mathrm{L}^{-1}\right)\end{array}$

In order to apply a multi-class model, $S P M$ have to be decomposed into particle groups gathering particles which have common settling properties. Then, the sorption properties of each group have to be investigated. This paper presents the protocol TALISMEN (French acronym for metal transfers at liquid/solid interfaces in natural water), a new experimental methodology for the fractionation of natural suspension into particle groups according to their effective settling velocity We. This method is based on a model applied to the temporal evolutions of the vertical distributions of the suspended solid concentrations. The proposed procedure allows the determination of the massic contribution and the effective settling velocity of each group. According to We, the bulk suspension is fractionated with a view to determine the physico-chemical properties and the sorption properties toward ${ }^{137} \mathrm{Cs}$ of the different particle groups.

\section{EXPERIMENTAL SET UP}

The settling device represented on figure 1 is made of a glass column $(1.5 \mathrm{~m} \mathrm{x} 0.46 \mathrm{~m} \times 0.46 \mathrm{~m})$. The tank bottom is designed as a two-part sediment collector that allows the isolation and extraction of the deposited solid. The first part is a $50^{\circ}$ angle funnel that minimises the collector volume. A large section valve $(0.22 \mathrm{~m}$ in diameter) enables the passage of deposited sediment towards the second part of the collector. This PVC transparent part is useful for a visual control of the settling. When the large section valve is closed, deposited solid can be extracted from the transparent collector by opening the bottom tap. The total water volume is $350 \mathrm{~L}$.

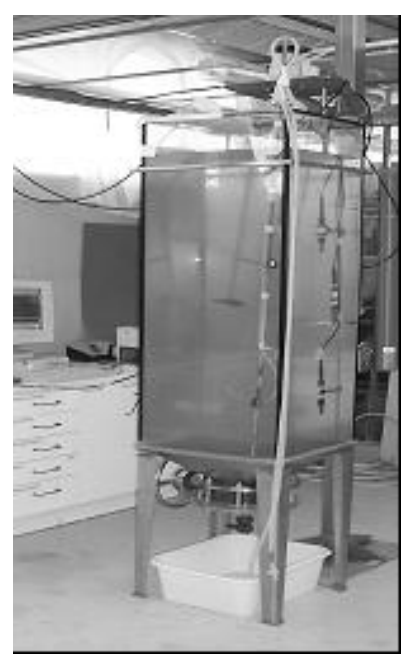

a) settling tank

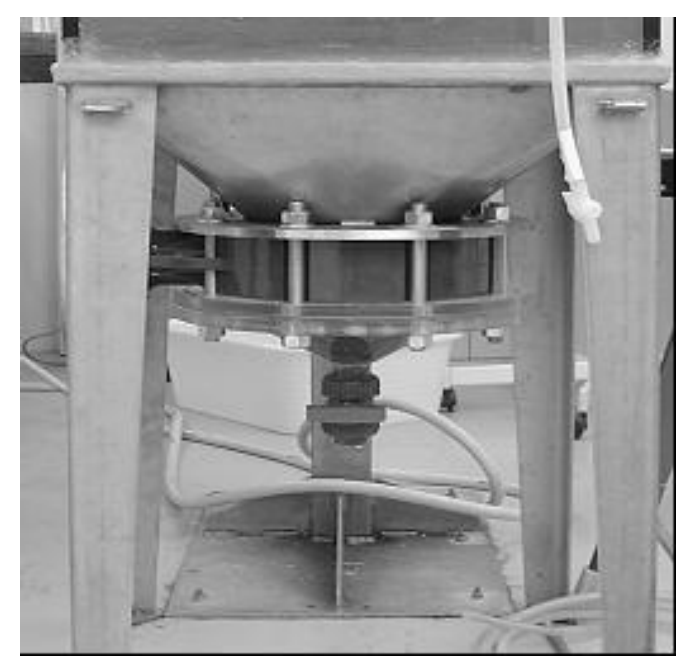

b) sediment collector

Figure 1. Photograph of the settling tank (a) and sediment collector (b). 
The settling tank is equipped with:

- A mechanical stirrer (Milton Roy Serie VDI, $1 \mathrm{~m}$ shaft length, $80 \mathrm{~mm}$ propeller diameter and speed in the range $0-750 \mathrm{rpm}$ ) is used to homogenise the suspension before any settling experiment. The propeller shaft is tilted with a $20^{\circ}$ angle with respect to the vertical in order to improve the mixing.

- A series of optical backscatter sensors (OBS-3, D\&A Instruments) immersed at different depths in the tank and connected to a data acquisition system (Agilent 34970A) are used to monitor the turbidity.

- Liquid sampling ports connected to a multi channel peristaltic pump (Masterflex serie 323 of high flow rate and variable speed) allow to perform simultaneous liquid phase sampling at the same depths as the turbidimetric probes.

Samples from the sediment collector and from the suspension in the tank are collected in polyethylene bottles (acid cleaned). They are stocked in dark at $4^{\circ} \mathrm{C}$ until their use.

Granulometric determinations of suspended and deposited solids are performed with a laser diffraction analyser (Master sizer S, MALVERN) equipped with a liquid cell and an automated sample dispersion unit (model MS 17, MALVERN). Prior to analysis, each sample is introduced into the dispersion unit and vigorously stirred in order to obtain a homogeneous particle suspension.

Particulate carbon (organic and inorganic) is determined by the use of a TOC analyser (Shimadzu SSM 5050-A). Solid materials are collected from the suspension and the sediment collector by centrifugation $(10000 \mathrm{rpm}, 25 \mathrm{~min})$. The supernatant is then eliminated and solid phases are dried at $105^{\circ} \mathrm{C}$ overnight before being grinded.

Sediment concentrations are determined by filtering a known sample volume through a pre-weighted glass fibre filter $(0.45 \mu \mathrm{m})$. Filters and retained materials are then dried overnight at $105^{\circ} \mathrm{C}$.

Experiments for the distribution coefficient $K d$ and sorption kinetics for ${ }^{137} \mathrm{Cs}$ are performed by batch techniques. Samples from the sediment collector and the suspension are poured into polycarbonate flasks. They are homogenised by vigorous stirring and sediment concentrations are determined. Then, samples are spiked with ${ }^{137} \mathrm{Cs}$. For different contact times, $20 \mathrm{ml}$ of sample are transferred into centrifuge tubes. Liquid and solid phases are separated by centrifugation (10 $000 \mathrm{rpm}, 25 \mathrm{~min})$. The supernatant is carefully removed for $\gamma$ spectrometry counting (GeHP detector). Initial radionuclide concentrations are determined by counting $20 \mathrm{ml}$ of each batch without separating solid and liquid phases.

\section{SETTLING EXPERIMENTS AND MODELLING}

The methodology is based on the assumption of an initially homogeneous suspended solid concentration obtained before any settling experiment by turbulent mixing. Turbidity monitoring thanks to OBS probes located at various depths begins right after mixing is activated. When stationary turbidity signals, characteristic of homogeneous conditions, are observed, the agitation is stopped and the settling phase begins at this time. The initial turbidity values acquired at $t=0$ are used as references for normalizing the turbidity signals. Turbidity values are recorded until they have decreased to a constant value. Signals recorded at each depth are then exploited with a two-step analysis.

The first step consists in decomposing the turbidity signal as a sum of exponentially decaying phases. As suggested by several authors, the temporal evolution of SSC during a settling experiment is assumed to be a first order decay rate process $[8,9]$. Considering a multi-class approach, we assume that the evolution of SSC could be mathematically described as the sum of several first-order exponential decays. Each term represents a settling particle group and is characterised by its massic contribution $S S C_{0}^{i}$ and its settling decay constant $\lambda^{i}(\mathrm{z})$.

$$
\operatorname{SSC}(z, t) \approx \sum_{i} S S C_{0}^{i} \cdot \exp ^{-\lambda^{i}(z) \cdot t}=\sum_{i} S S C^{i}(z, t)
$$


With: $\operatorname{SSC}(z, t) \quad$ Normalized suspended solid concentration at depth $z$ and time $t \quad(-)$

$S S C^{i}(z, t) \quad$ Group (i) contribution at depth $z$ and time $t$

$S S C^{i} \quad$ Group (i) initial contribution

$\lambda^{i}(z)^{0} \quad$ Group (i) decay rate at depth $z$

The optimal coefficient set $\left\{S S C_{0}^{i} ; \lambda^{i}(z)\right\}$ is determined by mathematical fitting between the experimental results and the model. Incrementing the number of terms in the exponential sum, the optimal number of particle groups $n$ is reached when the model fitting is not improved by the use of an additional group. This optimisation step is fully automated by the use of the Excel solver associated to VBA macros [10].

In a second step, the parameters obtained from mathematical fitting are used to compute the effective settling velocity. This parameter corresponds to the settling velocity averaged on the water column depth and is currently used for one-dimensional modelling of matter deposition fluxes. The following relation allows computing the temporal evolution of the group $i$ concentration in the tank:

$$
\frac{d S S C^{i}(t ; h)}{d t}=-\frac{W_{e}^{i}(t ; h)}{h} \cdot \operatorname{SSC}^{i}(t ; h)
$$

With: $\quad h \quad$ Water column depth

(m)

$S S C_{i}(t ; h) \quad$ Group $i$ contribution integrated on $h$ at time $t$

$W e^{i}(t ; h) \quad$ Group $i$ effective settling velocity integrated on $h$ at time $t \quad\left(\mathrm{~m} . \mathrm{s}^{-1}\right)$

According to equation (1), we can also write:

$$
\operatorname{SSC}^{i}(t ; h)=\frac{1}{h} \cdot \int_{0}^{h} \operatorname{SSC}^{i}(z, t) \cdot d z=\frac{S S C_{0}^{i}}{h} \cdot \int_{0}^{h} \exp ^{-\lambda^{i}(z) t} \cdot d z
$$

By replacing equation (3) in equation (2), the temporal evolution of the effective settling velocity $W e^{i}(t ; h)$ integrated on the water depth $h$ is obtained.

$$
W e^{i}(t ; h)=h \cdot \frac{\int_{0}^{h} \lambda^{i}(z) \cdot \exp ^{-\lambda^{i}(z) t} \cdot d z}{\int_{0}^{h} \exp ^{-\lambda^{i}(z) \cdot t} \cdot d z}
$$

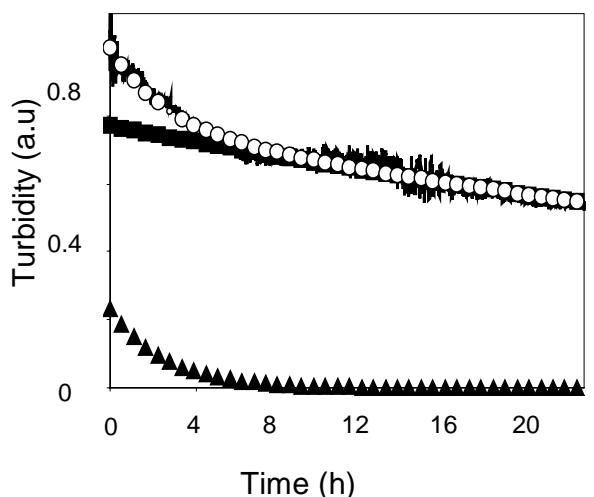

(a)

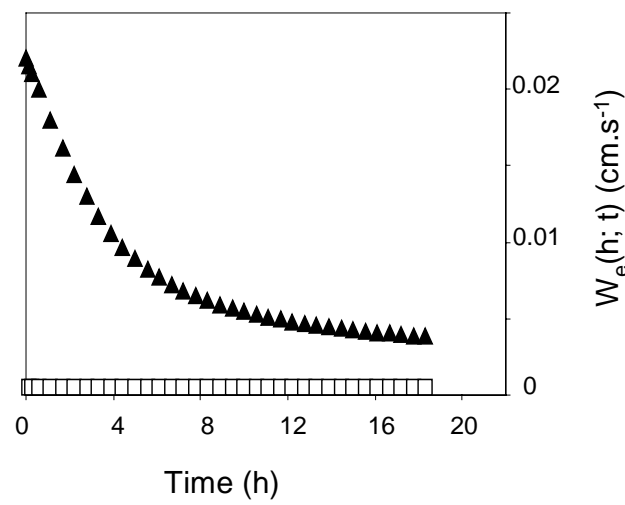

(b)

— Experimental signal $\quad \circ$ Fitted signal $\quad$ Group 1 - Group 2

Figure 2. Mathematical fitting of SSC profiles (a) and computation of the $W e^{i}(t ; h)$ (b) for a sample from the Rhône River. 


\section{SEPARATION AND CHARACTERISATION OF PARTICLE GROUPS}

The methodology used for the isolation and the collection of the particle groups is based on their specific residence time in the suspension. In calm water conditions, the application of a mono-dimensional settling model using the effective settling velocities allows the computation of both the composition of the suspension at a specific depth, and of the settled solids. The use of a set of valves of the sediment trap allows collecting the deposited sediment according to time. By selecting specific times of opening and closing, it is then possible to isolate mainly one group of particles. The sediment collector allows equally concentrating the particles that makes easier their physico-chemical characterization. For particle having very low settling velocities, in order to shorter the duration of the experiment, it is possible to collect them as suspended materials in the upper parts of the tank. As for the former case, times and sampling depths are defined by the settling model.

Figure 3 represents an example of the composition of suspension sampled from the Rhône River. According to the mathematical fitting this suspension is made of two settling groups. The group 1 represents the particles having the highest settling velocities. Its concentration decreases rapidly according to depth. On the contrary, group 2 gathers a whole of particles with weak settling velocities and a large residence time in the water column.

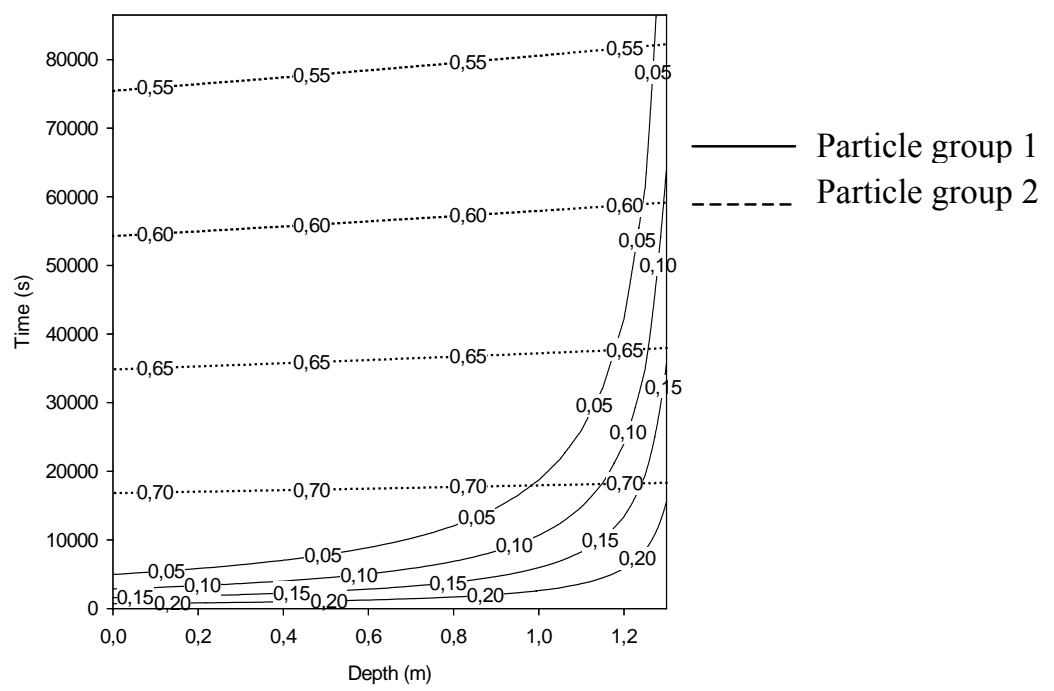

Figure 3. Temporal evolution of particle groups 1 and 2 contributions in the tank according to depth.

Once they are isolated, the particle groups are characterized by the determination of their granulometric distributions and by the determination of their percentage of organic and inorganic carbon.

The behaviour of the bulk suspension and particle groups towards ${ }^{137} \mathrm{Cs}$ is characterized by their $\mathrm{k}_{\mathrm{d}}$ and sorption kinetics. These parameters are estimated according to the evolution of ${ }^{137} \mathrm{Cs}$ in the liquid phase after different contact times as described in the experimental set up. As presented on figure 4 , the resulting temporal evolution of $K d$ is then fitted according to the following relation to obtain the $K d$ and sorption kinetics [11]:

$$
\operatorname{Kd}(\mathrm{t})=\operatorname{Kd}_{(\mathrm{eq})}\left(1-\mathrm{e}^{-\mathrm{k} . \mathrm{t}}\right)
$$

With: $K d(t)$ Distribution coefficient at time $\mathrm{t}$

$K d_{(e q)} \quad$ Estimated distribution coefficient

$k \quad$ Estimated sorption kinetic

( $\mathrm{L.kg}^{-1}$ )

$t$ time

(L.kg-1)

$\left(\mathrm{s}^{-1}\right)$ 


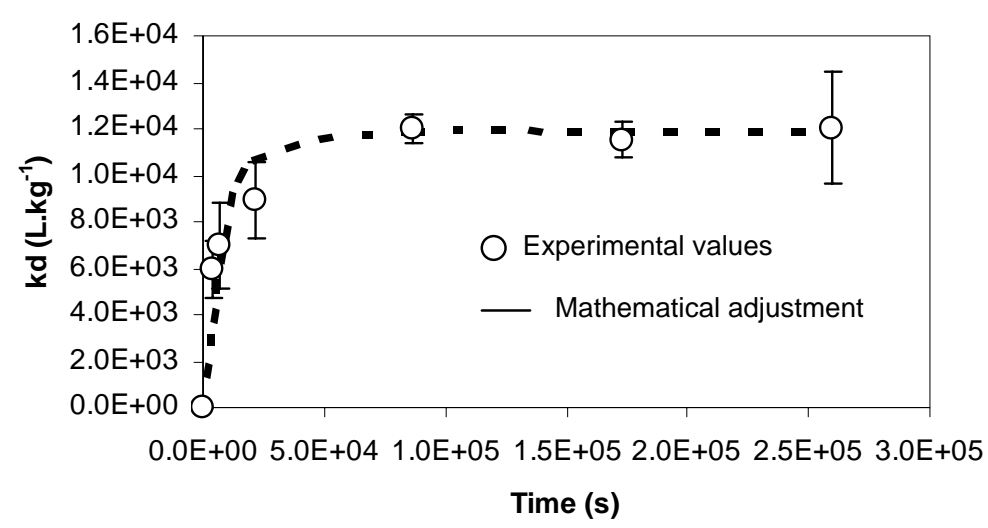

Figure 4. Example of estimation of $K d$ and sorption kinetics by mathematical adjustment for Rhone river bulk suspension.

\section{CONCLUSION}

This paper presents a method for the fractionation of suspended particulate matter in fresh water into particle groups according to the criterion of effective settling velocity. The proposed method TALISMEN (acronym for transfers of trace metals at liquid/solid interfaces in natural waters) is based on the mathematical exploitation of the suspended solid concentrations recorded during a settling experiment.

In a first step, the number of groups, their massic contributions, $S S C_{0}^{i}$, and their effective settling velocities, $W e^{i}(t ; h)$, are determined. In a second step, settling particle groups are characterized and their sorption properties ( $K d$ and sorption kinetics) toward ${ }^{137} \mathrm{Cs}$ are estimated. These parameters are some of the main required to consider the heterogeneity of a natural suspension for the calibration of models used for radionuclide transfers in river systems.

Since early summer 2004, the method is applied to the final part of the Rhone River. The objective is to characterize the settling groups according to the season and the hydraulic conditions in the final part of this river. At the same time the behaviour of the particle groups in relation to ${ }^{137} \mathrm{Cs}$ is studied to complete the parameter set needed for our water quality model.

\section{References}

[1] Walling D. E. and Moorehead P. W., "The particle size characteristics of fluvial suspended sediment: an overview". Hydrobiologia 176/177 (1989) 125-149.

[2] Ewais T. A., Grant A., and Abdel Fattah A. T., "The role of surface coating on sediments in sediments:water patitionning of trace elements and radionuclides". Journal of Environmental Radioactivity 49 (2000) 55-64.

[3] Walling D. E., Owens P. N., Waterfall B. D., Leeks G. J. L., and Wass, P. D., "The particle size characteristics of fluvial suspended sediment in the Humber and tweed catchments, UK". The Science of the Total Environment 251/252 (2000) 205-222.

[4] Boyer P., Beaugelin-Seiller K., Ternat F., Anselmet F., and Amielh M., "A dynamic box model to predict the radionuclide behaviour in rivers for medium and long-termperiods". Radioprotection 39(Suppl. 1) (2004)

[5] El Ganaoui O., "Contribution à la modélisation de l'influence de la dynamique sédimentaire sur les transferts des effluents liquides radioactifs dans les cours d'eau", Université de la Mediterranée/Ecole supérieure de mécanique de Marseille: MARSEILLE. (2002). 
[6] Sanada Y., Matsunaga T., Yanase N., Nagao S., Amano H., Tadaka H., and Tkachenko Y., "Accumulation and potential dissolution of Chernobyl-derived radionuclides in river bottom sediment". Applied Radiation and Isotopes 56 (2002) 751-760.

[7] Brach-Papa C., Boyer P., Ternat F., Amielh M., Anselmet F., "Experimental method for fractionation of natural suspension into particle groups according to their effective settling velocity". Water Research (submitted)

[8] Curran K. J., Hill P. S., and Milligan T. G., "Fine grained suspended sediment dynamics in the Eel River flood plume". Continental Shelf Research 22 (2002) 2537-2550.

[9] Prandle D., "Tidal characteristics of suspended sediment concentration". Journal of Hydraulic Engineering, 1997. 123 (1997) 341-350.

[10] Madoz C., Brach-Papa C., and Boyer P., "Caractérisation automatisée des classes de cinétique de dépôt au sein d'une suspension naturelle". Rapport IRSN/DEI-SECRE 03-12 (2003).

[11] Borretzen P. and Salbu B., "Fixation of Cs to marine sediments estimated by stochastic modelling approach". Journal of environmental Radioactivity 61 (2002) 1-20. 